\title{
Serum lipid profiles in patients with chronic kidney disease in a Saudi population
}

\begin{abstract}
Background and objective: Chronic kidney disease (CKD) is an increasing public health issue. Serum lipids might be independent risk factors for CKD. We aim to examine the association of serum lipid profiles, lipid ratios with CKD in a Saudi population.

Methods: We analyzed 3602 participants whom are between the ages 18 to 98 years. All patients were from the population of the diabetic centre and Primary health centre at King Fahad Armed Forces Hospital, Jeddah, Saudi Arabia.

Main results: A total of 3602 subjects (the mean age was $49.1 \pm 14.1$ years, minimum 18 years and maximum 98 years) were included in the analysis. $1358(37.7 \%)$ subjects were men and $700(19.4 \%)$ subjects had CKD. $391(28.8 \%)$ cases were male and 309 $(13.8 \%)$ cases were female with male to female ratio $2.1: 1, \mathrm{P}<0.0001$. Patients with CKD were significantly older than patients without CKD, $(57.1 \pm 12.9$ vs. $47.2 \pm$ 14.1 respectively, $\mathrm{p}<0.0001)$. Mean BMI was significantly higher in patients with than without CKD ( $31.6 \pm 6.4$ vs. $30.8 \pm 6.9$ respectively, $\mathrm{p}=0.006)$. Moreover, Patients with CKD have significantly higher prevalence of type 2 diabetes and hypertension than patients without CKD ( $85.5 \%$ and $64.9 \%$ respectively, $\mathrm{p}<0.0001)$. Patients with CKD have significantly higher mean and percentage of TC, LDL, TG and low HDL than patients without CKD, $\mathrm{p}<0.0001$. Patients with $\mathrm{CKD}$ had a higher TC/HDL ratio, $\mathrm{LDL} / \mathrm{HDL}$ ratio and TG/HDL ratio, than patients without $\mathrm{CKD}$, and all of these differences were significant $(p<0.0001)$. Male had significant higher serum TC, lower LDL and lower HDL than female $(\mathrm{p}<0.0001)$. Male had also a higher significant TG/ HDL ratio, a higher TC/HDL ratio and nonsignificant a higher LDL/HDL ratio than female. Percentage of TC, LDL, TG and low HDL CKD is non-statistically consistently increasing with age.
\end{abstract}

Conclusion: Dyslipidemia TC, LDL, TG and low HDL is high in patients with CKD. Moreover, TC/HDL, LDL/HDL and TG/HDL ratios were significantly high in patients with CKD. Thus, confirming presence of atherogenic lipid profile needing early intervention to prevent cardiovascular complications.

Keywords: dyslipidemia, chronic kidney disease, HDL, cardiovascular disease, diabetes
Volume 7 Issue I - 2019

\author{
Khalid S Aljabri,' Samia A Bokhari,' Muneera \\ A Alshareef,' Patan M Khan,' Hesham M \\ AbuElsaoud,' Mohammad M Jalal,' Rania F \\ Safwat,' Rehab El Boraie,' Nawaf K Aljabri,' \\ Bandari K Aljabri, ${ }^{3}$ Arwa Y Alsuraihi, ${ }^{3}$ Amjad I \\ Hawsawi $^{3}$ \\ 'Department of Endocrinology, King Fahad Armed Forces \\ Hospital, Kingdom of Saudi Arabia \\ ${ }^{2}$ Department of Laboratory, Northern Armed Forces Hospital, \\ Kingdom of Saudi Arabia \\ ${ }^{3}$ College of medicine, Um Al Qura University, Kingdom of Saudi \\ Arabia
}

Correspondence: Khalid SJ Aljabri, MD, FRCPC, FRCPC(Endo), FACP,ABIM, ABEM, Department of Endocrinology, King Fahad Armed Forces Hospital, Jeddah, Kingdom of Saudi Arabia, PO Box 9862, Jeddah 21 I 59, Kingdom of Saudi Arabia, Tel +966590008035, Fax +966(02)5760665.

Email khalidsaljabri@yahoo.com

Received: January 16, 2019 | Published: February 15, 2019

\section{Introduction}

Chronic kidney disease (CKD) is defined as increased urinary albumin excretion and reduced glomerular filtration rate or both and absolutely an epidemic of increasing prevalence with worldwide prevalence estimated to be $8-16 \% .^{1}$ Patients with CKD are at an increased risk for cardiovascular disease (CVD) and have a higher prevalence of hyperlipidaemia than the general population. ${ }^{2}$ The severity of lipid abnormalities correlates with proteinuria degree and is a common complication in patients with $\mathrm{CKD} .{ }^{2,3} \mathrm{CKD}$ shares some common risk factors, such as hypertension (HTN) and diabetes, with CVD.

Serum lipids might be independent risk factors for CKD. Previous studies were inconsistent. ${ }^{48}$ Dyslipidemia might be associated with renal dysfunction development and progression. ${ }^{9,10}$ One study found that higher total cholesterol (TC), higher non-HDL-cholesterol and lower HDL (HDL) were significantly associated with an increased risk of developing renal dysfunction. ${ }^{9}$

The recent Kidney Disease Outcomes Quality Initiative guidelines suggest that lipid abnormalities (TC, low density lipoprotein (LDL) and HDL, and triglyceride (TG) should be evaluated in patients with CKD. ${ }^{11}$ The National Cholesterol Education Program's Adult Treatment Panel criteria 2003 (NCEP ATPIII) suggests that anyone with hyperlipidaemia should undergo laboratory evaluation for secondary dyslipidaemias. ${ }^{12}$ There are limited data on the association of serum lipids with CKD in Saudi populations. The aim of the current study is to examine the association of serum lipid profiles, lipid ratios with CKD in a Saudi population.

\section{Methods}

We analyzed 3602 cases that are between the ages 18 to 98 years. All patients were from the population of the diabetic centre and Primary health centre at King Fahad Armed Forces Hospital, Jeddah, Saudi Arabia. All data were collected on the basis of a review of electronic medical data. All patients in the present study fulfilled the revised National Kidney Foundation criteria for the diagnosis of CKD. ${ }^{11}$ Weight $(\mathrm{kg})$ and height $(\mathrm{cm})$ were measured were recorded. Body mass index (BMI) was expressed as $\mathrm{kg} / \mathrm{m}^{2} .{ }^{13}$ Participants were defined as having type 2 diabetes mellitus (T2DM) according to selfreport, clinical reports, use of antidiabetic agents and $\mathrm{HbAlc}(\geq 6.5) .{ }^{14}$ HTN was defined when the systolic blood pressure was $\geq 130 \mathrm{~mm}$ $\mathrm{Hg}$ and/or diastolic blood pressure was $\geq 85 \mathrm{~mm} \mathrm{Hg}$ in addition to 
receiving any medication for hypertension. 15 The method used for determining the cholesterol and TG levels in the laboratory was the Enzmatic method. Dyslipidemia was defined according to the NCEP ATPIII, if one or more of the following are found: serum total TC level $\geq 5.18 \mathrm{mmol} / \mathrm{L}$, TG level $\geq 1.7 \mathrm{mmol} / \mathrm{L}$, LDL-C level $\geq 3.37$ $\mathrm{mmol} / \mathrm{L}$, and HDL-C- cholesterol level $<1.04 \mathrm{mmol} / \mathrm{L}$, and/or having received treatment for dyslipidemia during the previous 2 weeks. ${ }^{15,16}$ The total number of cohort were separated on basis of age values into five groups: $<30$ years, $30-39$ years, $40-49$ years, $50-59$ years and $\geq 60$ years.

\section{Statistical analysis}

Unpaired t-test analysis and Chi square (X2) test (categorical data comparison) were used between variables to estimate the significance of different between groups for demographic and clinical laboratory. All statistical analyses were performed using SPSS Version 23.0. The difference between groups was considered significant when $\mathrm{P}<0.05$.

\section{Results}

A total of 3602 subjects (the mean age was $49.1 \pm 14.1$ years, minimum 18 years and maximum 98 years) were included in the analysis. $1358(37.7 \%)$ subjects were men and $700(19.4 \%)$ subjects had CKD, Table 1. 391 (28.8\%) cases were male and $309(13.8 \%)$ cases were female with male to female ratio $2.1: 1, \mathrm{P}<0.0001$. Patients with CKD were significantly older than patients without CKD, (57.1 \pm 12.9 vs. $47.2 \pm 14.1$ respectively, $\mathrm{p}<0.0001)$. Mean BMI was significantly higher in patients with than without CKD (31.6 \pm 6.4 vs. $30.8 \pm 6.9$ respectively, $p=0.006$ ). Moreover, Patients with $C K D$ have significantly higher prevalence of T2DM, HTN than patients without CKD (85.5\% and $64.9 \%$ respectively, $\mathrm{p}<0.0001)$. Patients with CKD have significantly higher mean and percentage of TC, LDL, TG and low HDL than patients without $\mathrm{CKD}, \mathrm{p}<0.0001$. Patients with $\mathrm{CKD}$ had a higher TC/HDL ratio, a higher LDL/HDL ratio and TG/HDL ratio, than patients without $\mathrm{CKD}$, and all of these differences were significant $(\mathrm{p}<0.0001)$.

Male had significant higher serum TC, lower LDL and lower HDL than female $(\mathrm{p}<0.0001)$, Table 2 . Male had also a higher significant TG/HDL ratio, a higher TC/HDL ratio and nonsignificant a higher LDL/HDL ratio than female.

Percentage of TC, LDL, TG and low HDL CKD is consistently non-statistically increasing with age, Figure A-D.

Table I Baseline demographic and clinical characteristics of all subjects and patients with and without chronic kidney disease [mean \pm standard deviation or number (\%)]

\begin{tabular}{|c|c|c|c|c|c|c|}
\hline \multicolumn{3}{|c|}{ Parameters } & \multirow[t]{2}{*}{ All subjects 3602} & \multicolumn{2}{|c|}{ Chronic kidney disease } & \multirow[t]{2}{*}{ P value } \\
\hline \multirow{3}{*}{ Gender } & \multirow{2}{*}{\multicolumn{2}{|c|}{ Male }} & & Present 700 (19.4) & Absent 2902 (80.6) & \\
\hline & & & $1358(37.7)$ & $391(28.8)$ & $967(71.2)$ & \\
\hline & \multicolumn{2}{|l|}{ Female } & $2244(62.3)$ & $309(13.8)$ & $1935(86.2)$ & \\
\hline \multicolumn{3}{|c|}{ Age (years) } & $49.1 \pm 14.1$ & $57.1 \pm 12.9$ & $47.2 \pm 14.1$ & $<0.0001$ \\
\hline \multicolumn{3}{|c|}{ Body mass index $\left(\mathrm{kg} / \mathrm{m}^{2}\right)$} & $31.0 \pm 6.8$ & $31.6 \pm 6.4$ & $30.8 \pm 6.9$ & 0.006 \\
\hline \multicolumn{3}{|c|}{ Type 2 diabetes mellitus } & $1791(49.7)$ & $598(85.4)$ & $1193(41.1)$ & $<0.0001$ \\
\hline \multicolumn{3}{|c|}{ Hypertension } & $1256(34.9)$ & $454(64.9)$ & $802(27.6)$ & $<0.0001$ \\
\hline \multirow{2}{*}{\multicolumn{2}{|c|}{ Total cholesterol (mmol/l) }} & Mean \pm SD & $4.8 \pm 1.0$ & $4.9 \pm 1.2$ & $4.8 \pm 1.0$ & 0.001 \\
\hline & & $\geq 5.18$ & $1150(31.9)$ & $264(37.7)$ & $886(30.5)$ & $<0.0001$ \\
\hline \multirow{2}{*}{\multicolumn{2}{|c|}{ Low density lipoprotein ( $\mathrm{n}$}} & Mean \pm SD & $3.0 \pm 0.9$ & $3.1 \pm 1.0$ & $3.0 \pm 0.9$ & 0.001 \\
\hline & & $\geq 3.37$ & $864(31.2)$ & $230(37.2)$ & $634(29.4)$ & $<0.0001$ \\
\hline \multirow{2}{*}{\multicolumn{2}{|c|}{ Triglyceride (mmol/l) }} & Mean \pm SD & $1.6 \pm 1.0$ & $1.8 \pm 0.9$ & $1.5 \pm 1.0$ & $<0.0001$ \\
\hline & & $\geq 1.7$ & $1130(32.5)$ & $328(47.3)$ & $802(28.8)$ & $<0.0001$ \\
\hline \multirow{2}{*}{\multicolumn{3}{|c|}{ High density lipoprotein (mmol/1) }} & $1.2 \pm 0.3$ & $1.1 \pm 0.3$ & $1.2 \pm 0.3$ & $<0.0001$ \\
\hline & & & $916(32.7)$ & $285(45.5)$ & $631(29.0)$ & $<0.0001$ \\
\hline \multicolumn{3}{|c|}{ Total cholesterol/ High density lipoprotein } & $4.3 \pm 1.4$ & $4.7 \pm 1.5$ & $4.2 \pm 1.3$ & $<0.0001$ \\
\hline \multicolumn{3}{|c|}{ Low density lipoprotein / High density lipoprotein } & $2.6 \pm 1.1$ & $2.9 \pm 1.1$ & $2.6 \pm 1.0$ & $<0.0001$ \\
\hline \multicolumn{3}{|c|}{ Triglyceride / High density lipoprotein } & $1.5 \pm 1.2$ & $1.9 \pm 1.3$ & $1.4 \pm 1.1$ & $<0.0001$ \\
\hline \multicolumn{3}{|c|}{ Serum creatinine $(\mu \mathrm{mol} / \mathrm{L})$} & $72.3 \pm 30.1$ & $95.3 \pm 53.8$ & $66.8 \pm 16.3$ & $<0.0001$ \\
\hline
\end{tabular}


Table 2 Lipid Abnormalities by Target gender in subjects with chronic kidney disease

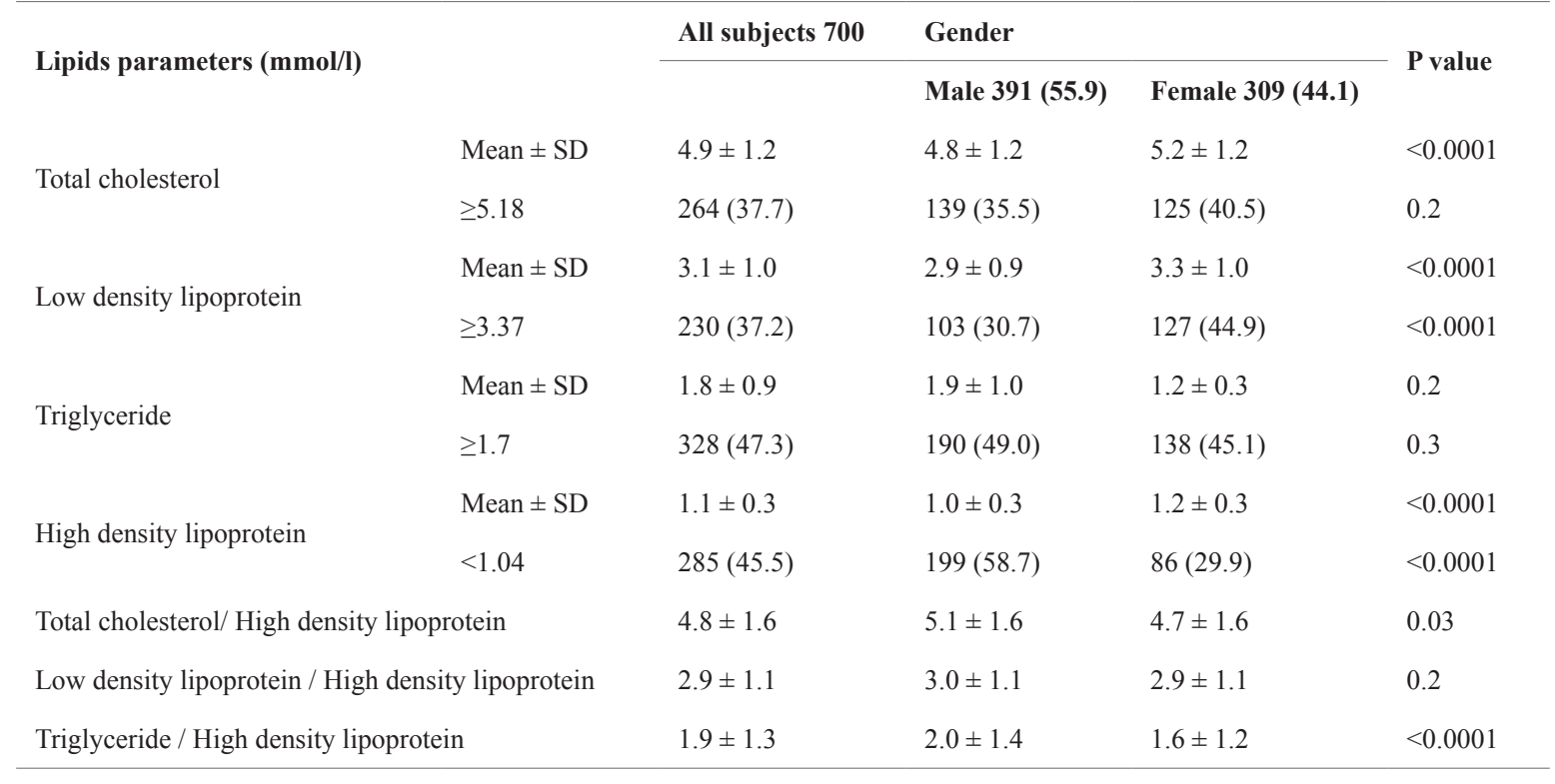
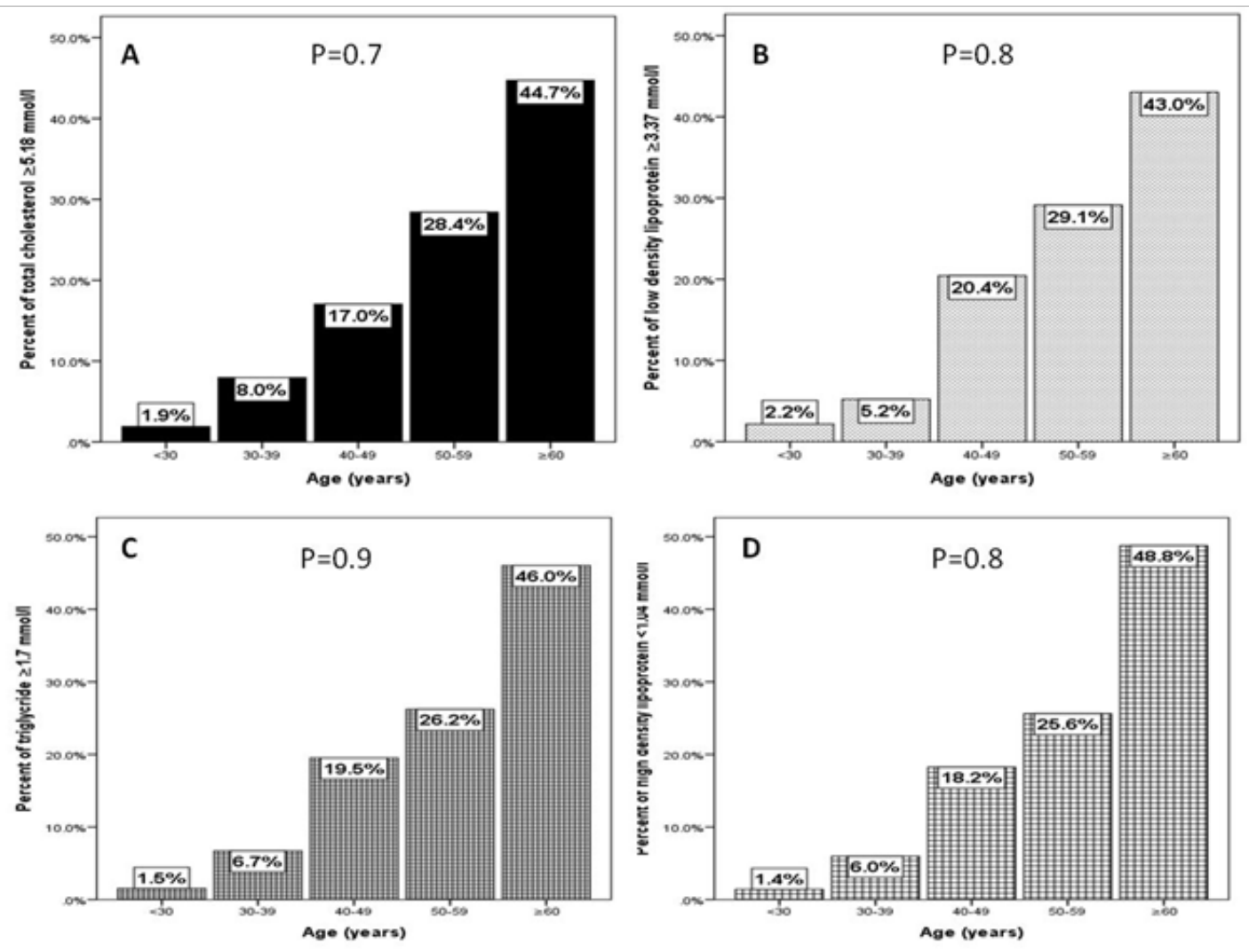

Figure A-D: Percent of lipids profiles in subjects with chronic kidney disease among age groups.

\section{Discussion}

We found that dyslipidemia, either higher TC, higher LDL, higher TG or lower HDL were associated with CKD. Moreover, in female, higher TC and higher LDL were associated with CKD.

Globally, increasing trend of CKD has put the health care facilities around the world under tremendous strain. Increase CVD morbidity and mortality in CKD is caused by dyslipidemia. Dyslipidemia seen in
CKD is characterized by high TG and low HDL levels, accumulation of remnant particles, predominance of LDL particles. ${ }^{17}$ Dyslipidemia might cause kidney damage and to play an important role in the progression of renal failure. ${ }^{18}$ Mesangial cells express receptors for LDL and oxidized LDL, which upon activation induce mesangial cell proliferation. Macrophages infiltration release cytokines causing damage to the endothelial cells, mesangial cells and podocytes leading to progressive renal damage. 
Various studies have shown that the prevalence of hyperlipidaemia in patients with CKD is higher than in the general population. ${ }^{2}$ The severity of lipid abnormalities is a common complication in patients with CKD. There have been few studies reporting the prevalence of dyslipidaemias in patients with $\mathrm{CKD} .^{2}$ Generally, the prevalence of hyperlipidaemia increases with deteriorating renal function and being proportional to the severity of renal impairment. However, diabetic CKD patients have higher TG and lower HDL suggesting that diabetes itself exacerbates lipid abnormalities in patients with renal impairment. ${ }^{19}$

Although, hyperlipidemia is independent risk factors for progression of $\mathrm{CKD}$, no conclusive evidences demonstrate that isolated hyperlipidemia can lead to CKD in healthy individuals. ${ }^{20}$ Recently, studies have demonstrated that statin therapy can halt the progression of kidney failure in patients with $\mathrm{CKD}^{21-25}$ The small, dense LDL phenotype is more commonly accompanied by the presence of hypertriglyceridemia, low HDL cholesterol levels, centrally obesity, and insulin resistance. An elevated level of TG and a low level of HDL are also components of metabolic syndrome. ${ }^{26}$ a Chinese study showed an increased number of metabolic syndrome components is associated with CKD. ${ }^{27}$ Several studies have been performed to assess the role of lipids in the development and progression of CKD. There was an independent association between high LDL levels and decline of renal function. ${ }^{28}$ They also reported an elevated LDL/HDL ratio (>4.4) which was associated with a worse loss of renal function. Similar conclusions were achieved by Muntner et al., ${ }^{29}$ evaluating over 2000 subjects. ${ }^{29}$ In particular, high TG and low HDL levels were independent risk factors for renal dysfunction. Conversely, cholesterol-LDL values were not predictive for increased risk of kidney injury.

Increased $\mathrm{TC} / \mathrm{HDL}$ ratio and $\mathrm{TG} / \mathrm{HDL}$ ratio indicative of atherogenic risk in CKD patients. We found to be high and was statistically significant $(p<0.0001)$ concordant with studies of Cheung et al., ${ }^{30}$ and Avram et al. ${ }^{31}$ The mean value of LDL/HDL ratio was statistically significant $(\mathrm{p}<0.0001)$ also high which is concordant to the studies of Cheung et al., ${ }^{30}$ and Avram et al. ${ }^{31}$ TG/HDL ratio can be used as a surrogate of insulin resistance and can be used to predict coronary heart disease independently. ${ }^{33-35} \mathrm{Kim}$ et al., ${ }^{36}$ used lipid ratios to predict CKD in Korean populations. The results indicated that TG/HDL-C ratio is the only lipid ratio associated with CKD. ${ }^{36}$ However, in the current study, found significant association of lipid ratios with CKD.

Saudi Arabia is ranked among the top 10 countries in the world for the prevalence of diabetes. ${ }^{37}$ The prevalence of T2DM is high among Saudi population and is estimated to be $34.1 \%$ in males and $27.6 \%$ in females ${ }^{38}$ Diabetes mellitus is the leading cause of CKD in both developed and developing countries..$^{39}$ The results of our study showed that the frequency of T2DM among patients with CKD was $85.4 \%$, which support that diabetes is the most common cause of CKD which was higher than previously reported $(33-69 \%))^{40-42}$ The difference in the prevalence estimated from this hospital based study and the previous community based study might be attributed to underdiagnoses of CKD in patients with T2DM. The difference could also due to an increase in the prevalence of diabetes and CKD as a complication of diabetes. A similar increase in the prevalence of diabetic kidney disease has been reported in a study carried in Tabuk, Saudi Arabia in the period 2009 to $2012 .{ }^{43}$ Mechanisms that lead to kidney disease in diabetes included hyperfiltration injury, advanced glycosylation end products and reactive oxygen species. ${ }^{44}$
HTN is well known to be a risk factor for CKD worldwide. ${ }^{45}$ The results of our study showed that the prevalence of HTN among patients with CKD was $64.9 \%$. A retrospective study of 540 Chinese patients with CKD found that $39.6 \%$ had HTN. ${ }^{46}$ In HTN, glomerular infiltration rate has been reported to decline faster compared to those without HTN ${ }^{47}$ Furthermore, some studies have found a close relation between the rate of decline of glomerular infiltration rate and the development of new onset CKD after a while in patients with HTN. ${ }^{48}$

\section{Strengths and limitations}

This study was a retrospective and not longitudinal, preventing determination of whether any risk factors were the cause or result of CKD. Finally, this study was based on a primary care population; thus, the correct sampling weights were not used for insufficient data, thus limiting the generalization of our results to the general population of Saudi Arabia.

\section{Conclusion}

It can be concluded from this study that dyslipidemia TC, LDL, TG and low HDL is high in patients with CKD. Moreover, TC/HDL, LDL/HDL and TG/HDL ratios were significantly high in patients with CKD. Thus, confirming presence of atherogenic lipid profile needing early intervention to prevent cardiovascular complications.

\section{Acknowledgments}

We are grateful to the staffs from the diabetic centre and Primary care department at King Fahad Armed Forces Hospital for their valuable contributions in data collection.

\section{Conflict of interest}

The authors have no conflict of interest to disclose.

\section{References}

1. Jha V, Garcia-Garcia G, Iseki K, et al. Chronic kidney disease: global dimension and perspectives. Lancet. 2013:382(9888):260-272.

2. Kasiske BL. Hyperlipidemia in patients with chronic renal disease. $A m$ J Kidney Dis. 1998;32(5 Suppl 3):S142-S156.

3. Culleton BF, Larson MG, Wilson PW, et al. Cardiovascular disease and mortality in a community-based cohort with mild renal insufficiency. Kidney Int. 1999;56(6):2214-2219.

4. Kurella M, Lo JC. Chertow GM. Metabolic syndrome and the risk for chronic kidney disease among nondiabetic adults. J Am Soc Nephrol. 2005;16(7):2134-2140

5. Kang HT, Shim JY, Lee YJ, et al. Association between the ratio of triglycerides to high-density lipoprotein cholesterol and chronic kidney diseasein Korean adults: The 2005 Korean national hHealth and nutrition examination survey. Kidney Blood Press Res. 2011;34(3):173179.

6. Kim JY, Kang HT, Lee HR, et al. Comparison of lipid-related ratios for prediction of chronic kidney disease stage 3 or more in Korean adults. $J$ Korean Med Sci. 2012;27(12):1524-1529.

7. Jiang L, Liang Y, Qiu B, et al. Metabolic syndrome and chronic kidney disease in a rural Chinese population. Clin Chim Acta. 2011;412(2122):1983-21988.

8. Cheng HT, Huang JW, Chiang CK, et al. Metabolic syndrome and insulin resistance as risk factors for development of chronic kidney disease and rapid decline in renal function in elderly. J Clin Endocrinol Metab. 2012;97(4):1268-1276. 
9. Schaeffner ES, Kurth T, Curhan GC, et al. Cholesterol and the risk of renal dysfunction in apparently healthy men. J Am Soc Nephrol. 2003;14(8):2084-2091

10. Hovind P, Rossing P, Tarnow L, et al. Remission and regression in the nephropathy of type 1 diabetes when blood pressure is controlled aggressively. Kidney Int. 2001;60(1):277-283.

11. Isakova T, Nickolas TL, Denburg M, et al. KDOQI US Commentary on the 2017 KDIGO Clinical Practice Guideline Update for the Diagnosis, Evaluation, Prevention, and Treatment of Chronic Kidney Disease-Mineral and Bone Disorder (CKD-MBD). Am J Kidney Dis. 2017;70(6):737-751

12. Stone NJ, Robinson JG, Lichtenstein AH, et al, 2013 ACC/AHA guideline on the treatment of blood cholesterol to reduce atherosclerotic cardiovascular risk in adults: a report of the American College of Cardiology/American Heart Association Task Force on Practice Guidelines. J Am Coll Cardiol. 2014;63(25 Pt B):2889-2934.

13. Chen YM, Ho SC, Lam SS, et al. Validity of body mass index and waist circumference in the classification of obesity as compared to percent body fat in Chinese middle-aged women. Int $J$ Obes (Lond). 2006;30(6):918-925.

14. American Diabetes Association. Classification and Diagnosis of Diabetes: Standards of Medical Care in Diabetes-2018. Diabetes Care. 2018;41(Supplement 1):S13-S27.

15. Whelton PK, Carey RM, Aronow WS, et al. ACC/AHA/AAPA/ABC/ ACPM/AGS/APhA/ASH/ASPC/NMA/PCNA Guideline for the Prevention, Detection, Evaluation, and Management of High Blood Pressure in Adults: A Report of the American College of Cardiology/ American Heart Association Task Force on Clinical Practice Guidelines. Hypertension. 2018;71(6):1269-1324.

16. Jellinger PS, Smith DA, Mehta AE, et al. American association of clinical endocrinologists guidelines for management of dyslipidemia and prevention of atherosclerosis. Endocr Pract. 2012;18(Suppl 1):178

17. Attman PO, Samuelsson O, Alaupovic P. Lipoprotein metabolism and renal failure. American J Kidney Dis. 1993;21:573-592.

18. Chen SC, Hung CC, Kuo MC, et al. Association of dyslipidemia with renal outcomes in chronic kidney disease. PLoS One. 2013;8(2):e55643.

19. Attman PO, Nyberg G, William-Olsson T, et al. Dyslipoproteinemia in diabetic renal failure. Kidney Int. 1992;42(6):1381-389.

20. Trevisan R, Dodesini AR, Lepore G. Lipids and renal disease. J Am Soc Nephrol. 2006;17(4 Suppl 2):S145-S147.

21. Shepherd J, Kastelein JJ, Bittner V, et al. Effect of intensive lipid lowering with atorvastatin on renal function in patients with coronary heart disease: the Treating to New Targets (TNT) study. Clin J Am Soc Nephrol. 2007;2(6):1131-1139.

22. Athyros VG, Mikhailidis DP, Papageorgiou AA, et al. The effect of statins versus untreated dyslipidaemia on renal function in patients with coronary heart disease. A subgroup analysis of the Greek atorvastatin and coronary heart disease evaluation (GREACE) study. J Clin Pathol. 2004;57(7):728-734.

23. Bianchi S, Bigazzi R, Caiazza A, et al. A controlled, prospective study of the effects of atorvastatin on proteinuria and progression of kidney disease. Am J Kidney Dis. 2003;41(3):565-570.

24. Koren MJ, Davidson MH, Wilson DJ, et al. Focused atorvastatin therapy in managed-care patients with coronary heart disease and CKD. Am J Kidney Dis. 2009;53(5):741-750.

25. Austin MA. Hokanson JE. Epidemiology of triglycerides, small dense low-density lipoprotein, and lipoprotein (a) as risk factors for coronary heart disease. Med Clin North Am. 1994;78(1):99-115.
26. National Cholesterol Education Program (NCEP) Expert Panel on Detection Ea, and Treatment of High Blood Cholesterol in Adults (Adult Treatment Panel III). Third report of the national cholesterol education program (NCEP) expert panel on detection, evaluation, and treatment of high blood cholesterol in adults (Adult Treatment Panel III) final report. Circulation. 2002;106(25):3143-3421.

27. Jiang L, Liang Y, Qiu B, et al. Metabolic syndrome and chronic kidney disease in a rural Chinese population. Clin Chim Acta. 2011;412(2122):1983-1988

28. Mänttäri M, Tiula E, Alikoski T, et al. Effects of hypertension and dyslipidemia on the decline in renal function. Hypertension 1995;26(4):670-675.

29. Muntner P, Coresh J, Smith JC, et al. Plasma lipids and risk of developing renal dysfunction: the atherosclerosis risk in communities study. Kidney Int. 2000;58(1):293-301.

30. Cheung AK, Wu LL, Kablitz C. Atherogenic lipids and lipoproteins in hemodialysis patients. Am J Kidney Dis. 1993;22(2):271-276.

31. Avram MM, Goldwasser P, Burrell DE. The uremic dyslipidemia: a cross sectional and longitudinal study. Ame J Kidney Dis. 1992;20(4):324-35.

32. Cases A, Coll E. Dyslipidemia and progression of renal disease in chronic renal failure patients. Kidney Int Suppl. 2005;(99):S87-S93.

33. Coresh J, Kwiterovich PO, Smith $\mathrm{HH}$, et al. Association of plasma triglyceride concentration and LDL particle diameter, density, and chemical composition with premature coronary artery disease in men and women. J Lipid Res. 1993;34:1687-1697.

34. Lamarche Lamarche B, Lemieux I, Despres JP. The small, dense LDL phenotype and the risk of coronary heart disease: epidemiology, pathophysiology and therapeutic aspects. Diabetes Metab. 1999;25(3):199211

35. Onat A, Can G, Kaya H, et al. "Atherogenic index of plasma" ( $\log 10$ triglyceride/high-density lipoprotein-cholesterol) predicts high blood pressure, diabetes, and vascular events. J Clin Lipidol. 2010;4(2):89-98.

36. Kim JY, Kang HT, Lee HR, et al. Comparison of lipid-related ratios for prediction of chronic kidney disease stage 3 or more in Korean adults. $J$ Korean Med Sci. 2012;27(12):1524-1529.

37. Edition IDAS: International Diabetes Federation. 2013.

38. Alqurashi KA, Aljabri KS, Bokhari SA. Prevalence of diabetes mellitus in a Saudi community. Ann Saudi Med. 2011;31(1):19-23.

39. McClellan WM, Flanders WD. Risk factors for progressive chronic kidney disease. J Am Soc Nephrol. 2003;14(7 Suppl 2):65-70.

40. Muflih AS, Sultan TAM, Taiwilaa AF. Prevalence and Risk Factors for Gallstone Disease in Hail Region. The Egyptian Journal of Hospital Medicine. 2018;70(4):703-707.

41. Ahmed HG, Ginawi IA, Al-hazimi AM. Prevalence Estimates of Chronic Kidney Disease in Hail Region, KSA: in a Comprehensive Survey. International Journal of Science and Research. 2014;3:252 256.

42. Ghannam AA, Muflih AA, Fazaa AF. Prevalence of Diabetes among Patients with Chronic Kidney Disease in Hail Region. The Egyptian Journal of Hospital Medicine. 2018;71(2):2434-2442.

43. El Minshawy O, Ghabrah T, El Bassuoni E. Diabetic nephropathy as a cause of end-stage renal disease in Tabuk area, Saudi Arabia: a fouryear study. Saudi J Kidney Dis Transpl. 2014;25(5):1105-1109.

44. Reidy K, Kang HM, Hostetter T, et al. Molecular mechanisms of diabetic kidney disease. The Journal of Clinical Investigation. 2014;124(6):2333-2340.

45. Barri YM. Hypertension and kidney disease: a deadly connection. Curr Hypertens Rep. 2008;10(1):39-45. 
46. Xie Y, Chen X. Epidemiology, major outcomes, risk factors, prevention and management of chronic kidney disease in China. Am J Nephrol. 2008;28(1):1-7.

47. Hanratty R, Chonchol M, Miriam Dickinson L, et al. Incident chronic kidney disease and the rate of kidney function decline in individuals with hypertension. Nephrol Dial Transplant. 2010; 25(3):801-807.
48. Yook CC, Siew MC. Hypertension and the development of new onset chronic kidney disease over a 10 year period: a retrospective cohort study in a primary care setting in Malaysia. BMC Nephrology. 2012;13:173. 